Lukács A, Mayer K, Juhász E, Varga B, Fodor B, et al. (2012) Reduced physical fitness in children and adolescents with type 1 diabetes. Pediatr Diabetes 13: 432-437.

\title{
Reduced physical fitness in children and adolescents with type 1 diabetes
}

\author{
A. Lukács ${ }^{1}$, K. Mayer ${ }^{2}$, E. Juhász ${ }^{3}$, B. $\operatorname{Varga}^{4}$, B. Fodor ${ }^{1}$, L. Barkai ${ }^{1,5}$
}

${ }^{1}$ University of Miskolc, Faculty of Health Care, Department of Theoretical Health Sciences, Miskolc, Hungary

${ }^{2}$ University of Miskolc, Faculty of Health Care, Department of Physical Education, Miskolc, Hungary

${ }^{3}$ University of Miskolc, Faculty of Health Care, Department of Physiotherapy, Miskolc, Hungary

${ }^{4}$ University of Miskolc, Faculty of Economics, Institute of Business Information and Methods, Miskolc, Hungary

${ }^{5}$ University of Debrecen, Medical and Health Science Center, Postgraduate Institute of

Pediatrics and Borsod County University Hospital, Miskolc, Hungary

\section{SUMMARY}

Aims: To evaluate motor performance and cardiorespiratory function in youths with type 1 diabetes in comparison with age-matched control group; and to analyse the influence of physical activity level, anthropometric and physical fitness parameters on long-term metabolic control.

Methods: 106 youths with diabetes and 130 healthy youths aged 8-18 were assessed by the Eurofit Test Battery regarding motor performances, cardiorespiratory fitness $\left(\mathrm{VO}_{2 \max }\right)$, skinfold thickness, and body mass index. Physical activity level was assessed through the use of questionnaires. Predictors of physical fitness and metabolic control were determined with regression analysis.

Results: There were no differences either in body composition or in physical activity level, but younger girls with diabetes had impaired results in speed of upper limb movement, abdominal muscle strength, upper body strength, running speed and $\mathrm{VO}_{2 \max }$; older girls with diabetes had poor results in speed of upper limb movement, abdominal muscle strength, upper body strength and $\mathrm{VO}_{2 \max }$. Younger boys with diabetes had impaired results in speed of upper limb movement, flexibility, static strength of the hand and abdominal muscle strength; and older boys with diabetes had poor results in speed of upper limb movement, flexibility, abdominal muscle strength, upper body strength and $\mathrm{VO}_{2 \max }$. Older age, female gender, higher skinfold thickness, lower physical activity level and higher $\mathrm{HbA}_{1 \mathrm{c}}$ were significant independent predictors of poorer $\mathrm{VO}_{2 \max }$. Better $\mathrm{VO}_{2 \max }$ proved to be the single predictor of favourable $\mathrm{HbA}_{1 \mathrm{c}}$.

Conclusions: Youths with diabetes have reduced fitness parameters. Efforts should be carried out to improve physical fitness as part of treatment and care of children and adolescents with type 1 diabetes.

KEY WORDS: type 1 diabetes, children, adolescence, exercise, glycaemic control 


\section{ABBREVIATIONS:}

BAH, Bent arm hang; BMI, Body mass index; ESR, Endurance shuttle run; FLB, Flamingo balance; HGR, Hand grip; PAQ-A, Physical Activity Questionnaire for Older Children; PAQC, Physical Activity Questionnaire for Adolescents; PLT, Plate tapping; SAR, Sit and reach; SBJ, Standing broad jump; SD, Standard deviation; SHR, Shuttle run; SUP, Sit-ups; T1DM, type 1 diabetes mellitus; y/o, years old; $\mathrm{VO}_{2 \max }$, maximal oxygen uptake

\section{INTRODUCTION}

The beneficial effects of physical activity and the advantages of good physical fitness either in healthy or chronically ill conditions are well known. Regular exercise is considered an integral part of the treatment and care of type 1 diabetes in children, adolescents and adults and recommendations for patients are well defined by international guidelines [1, 2]. Nevertheless, few data are available regarding investigation of physical fitness in type 1 diabetes, especially in children and adolescents. In a study from Finland, physical work capacity as measure of physical fitness was impaired in boys with diabetes [3]. Lower cardiorespiratory fitness in conjunction with female gender was found in a cross-sectional study in different groups of children with chronic diseases, including type 1 diabetes [4]. A small study from Poland investigating physical fitness by motor performance tests suggested that type 1 diabetes teenagers have poorer results than the healthy local population [5]. Another Australian study investigated cardiorespiratory fitness in children with type 1 diabetes and observed reduced levels in association with female sex [6]. It has also been suggested that lower level of cardiorespiratory fitness in patients could be due to either lower physical activity level $[4,6]$ or pathophysiological changes resulting from diabetes, e.g. poor metabolic control $[3,6,7]$. However, these studies used tests assessing cardiorespiratory function [3, 4, 6, 7] or motor performances [5] separately and no studies assessed these functions parallel.

The aim of our study was to evaluate both motor performance and cardiorespiratory fitness as measures of physical fitness using the complex, internationally recommended and widely used Eurofit physical fitness test battery in children and adolescents with type 1 diabetes in comparison with control group without diabetes. The aim of the study was also to assess predictors of physical fitness in these patients and to analyse the influence of physical activity level, anthropometric and physical fitness parameters on the long-term metabolic control.

\section{PATIENTS AND METHODS}

\section{Patients and settings}

One hundred six youths with diabetes (53 girls and 53 boys) and 130 healthy youths (69 girls and 61 boys) aged 8-18 yr participated in the study. Table 1 presents the data of the subjects by age and gender. Exclusion criteria for diabetic participants were cognitive disabilities or another serious chronic illness affecting the patient's ability to perform the motor tests. Diabetic patients were recruited from the patient population of the Pediatric Diabetes Centre of Borsod-Abaúj-Zemplén County University Hospital providing diabetes care for the northeastern region Hungary. The duration of diabetes was at least $1 \mathrm{yr}$ and the participants had no evidence of diabetic complications by regular assessments for retinopathy (fundal photography), nephropathy (microalbuminuria), and neuropathy (nerve conduction velocity 
and cardiovascular reflex tests). Age-matched comparison groups were selected from local schools. There were no exclusion criteria other than applied for diabetic subjects. All the students who attended the Physical Education classes and were able to perform the Eurofit tests were invited to participate in the study. There were no parents and children who declined to participate in the study. To have comparable groups for analyzing the results, diabetic and control subjects were divided into four groups according to age and gender, respectively: younger girls (8-12 yr), younger boys (8-12 yr), older girls (13-18 yr), older boys (13-18 yr). All the participants were white/non-Hispanic by ethnicity.

The diabetic and non-diabetic participants and their parents were informed about the purpose and the methods of the study verbally and in written form. Before completing the procedures, parents gave written consent, and the children gave their assent. The study was approved by the Borsod-Abaúj-Zemplén County Regional Scientific and Research Ethics Committee.

\section{Measures}

The physical fitness of the subjects was investigated with the standardized Eurofit Physical Fitness Test Battery that was devised by the Committee of Experts for Sports Research of the Council of Europe [8]. This battery examines nine tests: eight motor performance tests and the cardiorespiratory fitness test. 1-Motor performance tests consist of the evaluation of the total body balance (Flamingo test, FLB), 2-speed and coordination of upper limb movement (Plate tapping test, PLT), 3-general flexibility (Sit and reach test, SAR), 4-explosive strength of legs (Standing broad jump test, SBJ), 5-static strength of the hand and forearm (Hand grip test, HGR), 6-abdominal muscle strength (Sit-up test, SUP), 7-upper body strength (Bent arm hang test, BAH), and 8-running speed - agility (10 x 5 meter shuttle run test, SHR). 9-the test for cardiorespiratory fitness utilizes the maximal oxygen uptake $\left(\mathrm{VO}_{2 \max }\right)$ as the single best measure of maximal aerobic power [9]. The $\mathrm{VO}_{2 \max }$ was predicted from the 20-m endurance shuttle run test using regression equation proposed by Léger at al $[10,11]$. The validity of the test in prediction of maximal oxygen consumption has been previously established [12, 13]. Certified physical education teachers conducted all tests according to the Eurofit protocol. Motor performance and cardiorespiratory fitness tests were carried out at 08.00-10.00 hours. If the patient's morning home blood glucose result was out of the target range $(5-10 \mathrm{mmol} / \mathrm{L})$, a new appointment was given to perform the test on another day.

To assess and compare body composition and physical activity levels in the study groups, anthropometric measurements were recorded and a validated questionnaire evaluation was given to each participant. An estimation of body fat by skinfold thickness measurements was made at four sites (biceps, triceps, subscapular and suprailiac) on the right side of the body by the same experienced observer in the standard manner using a Harpenden skinfold calliper (HSB-BI, British Indicators Ltd., UK) according to the International Society for the Advancement of Kinanthropometry [14]. Two non-consecutive measurements for all sites were performed and mean values were used analyzing the data. As there is no standard for evaluating body fat content in percentage for children and adolescents, the skinfold thickness was summed in millimeter. Height (to the nearest $0.5 \mathrm{~cm}$ ) and weight (accurate to $0.1 \mathrm{~kg}$ ) were measured to evaluate the BMI in light sport clothing without shoes. The Physical Activity Questionnaire for Older Children (PAQ-C) and the Physical Activity Questionnaire for Adolescents (PAQ-A) were applied to assess physical activity levels of the patients and controls $[15,16]$. These tests are self-administered, 7-day recall validated questionnaires that 
provide general measure of physical activity for youths from ages 8 to 19 yr. They classify children and adolescents into five different activity levels. A score of 1 indicates low physical activity, whereas a score of 5 indicates high physical activity. The closest haemoglobin A1c $\left(\mathrm{HbA}_{1 \mathrm{c}}\right)$ obtained in the routine care was used to assess long-term metabolic control of the patients.

\section{Statistical analysis}

Descriptive characteristics (mean and SC) were performed for all parameters. SPSS 19.0 statistical analysis software was used for data analyses and $\mathrm{p}$ values $\leq 0.05$ were considered statistically significant. The Shapiro-Wilk test was used to evaluate normality of the data set. To compare the results of diabetic and the control groups, independent t-test and MannWhitney $\mathrm{U}$ test were used according to the normality of distribution. The correlations between Eurofit test results and metabolic control were assessed by Spearman's correlation. Multiple regression analysis was carried out to establish predictors of physical fitness and the metabolic control.

\section{RESULTS}

\section{Anthropometric characteristics and physical activity levels}

No significant differences in body composition expressed by skinfold thickness and BMI were observed between the diabetic and control groups. Physical activity levels of the patient groups did not differ significantly from the control children as assessed by PAQ-C and PAQA (Table 1).

\section{Physical fitness}

Eurofit test results in 5 and 4 of 9 tests applied were poorer in the groups of child and adolescent girls with diabetes as compared with their healthy peers, respectively. Younger girls with diabetes had significantly poorer results on the PLT test, SUP test, BAH test, SHR test, and $\mathrm{VO}_{2 \max }$ than age-matched control girls. Older girls with diabetes had significantly poorer results on the PLT test, SUP test, BAH test, and $\mathrm{VO}_{2 \max }$ than age-matched control girls. Table 2 presents results obtained by the Eurofit battery for girls with diabetes and their age-matched controls. Results in 4 and 5 of 9 tests applied were poorer in the groups of younger and older boys with diabetes as compared with their non-diabetic controls, respectively. Younger boys with diabetes had significantly lower achievement on the PLT test, SAR test, HGR test and SUP test than age-matched control boys. Older boys with diabetes had significantly poorer results on the PLT test, SAR test, SUP test, BAH test, and $\mathrm{VO}_{2 \max }$ than age-matched control boys. Table 3 presents results of Eurofit tests for boys with diabetes and the age-matched control boys.

\section{Predictors of metabolic control and physical fitness}

Of the 9 Eurofit tests applied, $\mathrm{VO}_{2 \max }(\mathrm{r}=-0.413 ; \mathrm{p}<0.001)$, SUP test $(\mathrm{r}=-0.215 ; \mathrm{p}=0.027)$ and SHR test $(\mathrm{r}=0.195 ; \mathrm{p}=0.045)$ correlated significantly with $\mathrm{HbA}_{1 \mathrm{c}}$ as measure of long-term metabolic control. When $\mathrm{HbA}_{1 \mathrm{c}}$ was used as dependent variable in the multiple regression model, better $\mathrm{VO}_{2 \max }$ proved to be the single significant predictor of favourable $\mathrm{HbA}_{1 \mathrm{c}}(\mathrm{B}=-$ 0.077, $\left.\mathrm{SE}(\mathrm{B})=0.021, \quad \beta=-0.343, \mathrm{t}=-3.726, \mathrm{p}<0.001 ; \mathrm{R}^{2}=0.118\right)$. Age, gender, diabetes 
duration, height, weight, BMI, skinfold thickness, physical activity level, general balance, flexibility, speed of limb movement, running speed, static strength, dynamic strength and muscular endurance (independent variables) were not significant in the model. Therefore, in further analysis to establish predictors of physical fitness, $\mathrm{VO}_{2 \max }$ was used as dependent variable. In non-diabetic control subjects, higher age, female gender, higher skinfold thickness, and lower physical activity level were independently associated with lower $\mathrm{VO}_{2 \max }$ explaining $53.5 \%$ of its variation. In subjects with diabetes, older age, female gender, higher skinfold thickness, lower physical activity level and higher $\mathrm{HbA}_{1 \mathrm{c}}$ proved to be significant independent predictors of poorer $\mathrm{VO}_{2 \max }$ explaining $65.1 \%$ of its variance (Table 4). Age, height, weight, BMI, skinfold thickness and morning home blood glucose as independent variables were not significant in the model.

\section{DISCUSSION}

In this study, we investigated the motor performance and cardiorespiratory fitness of children and adolescents with type 1 diabetes using the standardized Eurofit test battery and compared results with age-matched control groups. Patients with diabetes of both sexes produced substantially poorer physical fitness levels in several tests than their non-diabetic peers. Female gender, increasing age, higher skinfold thickness, lower physical activity level, and poor long-term metabolic control were significant independent predictors of lower $\mathrm{VO}_{2 \max }$ as a measure of cardiorespiratory fitness. Furthermore, of the Eurofit tests, anthropometric and physical activity parameters used, $\mathrm{VO}_{2 \max }$ influenced independently the long-term metabolic control.

Few previous studies have addressed the assessment of physical fitness in children with type 1 diabetes. These studies investigated cardiorespiratory fitness comparing results with nondiabetic children. Except for one study, in which prepubertal boys were investigated [17], all investigations observed reduced cardiorespiratory performance in children and adolescents with diabetes $[3,4,6,18]$. To our knowledge, this is the first trial, in which parallel assessments of motor performances, and cardiorespiratory function were carried out in youths with type 1 diabetes using Eurofit test battery. These tests are standardized and widely used methods of estimation the complex physical fitness of children and adolescents. According to the present results, all diabetic groups had impaired speed and coordination of upper limb movement and abdominal muscle strength. In addition, all girls with diabetes had less upper body strength and maximal oxygen uptake; furthermore, younger girls with diabetes had poorer running speed as well. Moreover, all boys with diabetes had poor general flexibility and younger boys with diabetes had poor static strength of hand and forearm and older boys with diabetes showed less upper body strength and maximal oxygen uptake. In a previous study, children with diabetes had lower achievement in body balance, long jump and handgrip tests; however this study did not investigate cardiorespiratory fitness [5]. In another study, pre-pubertal boys with diabetes had normal cardiorespiratory fitness [17] similarly to the present study where younger boys with diabetes also had no impairment of this parameter.

The reason why youths with diabetes showed impaired performances on various tests for physical fitness is not clear. It has been suggested that lower physical activity or physiological changes resulting from the pathology of diabetes itself could result in reduced fitness in children $[4,6]$. In this study, physical activity level and skinfold thickness also 
influenced cardiorespiratory performance in healthy subjects and patients with diabetes. Nevertheless, the groups with diabetes did not differ from the control groups regarding body composition and physical activity level. Despite these facts, it is conceivable that youths with diabetes, because of the fear of hypoglycaemia as a consequence of exercise, participate less intensively in sport activities, have less daily physical activity, and may have less skill to perform such tests than non-diabetic peers. However, this concept should be assessed prospectively in the future.

Another assumption is that long-term metabolic control influences the fitness of patients with diabetes. Previous studies showed that poor metabolic control is associated with poor cardiorespiratory fitness in children with diabetes $[3,6,7]$. In our study, $\mathrm{HbA}_{1 \mathrm{c}}$ was independent predictor of $\mathrm{VO}_{2 \max }$. Interestingly, the $\mathrm{VO}_{2 \max }$ was the only predictive parameter for metabolic control and the other tests representing motor performances had no effect. This finding emphasizes the importance of physical fitness in the care of diabetes and suggests that improvement in physical condition may contribute to better diabetes control which in turn leads to further improvement in physical performance. Our finding of $\mathrm{VO}_{2 \max }$ being the only predictive parameter for $\mathrm{HbA}_{1 \mathrm{c}}$ also suggest the importance of aerobic exercise in achieving and maintaining good glycemic control. Although, children and adolescents need all types of movements for improving different physical abilities and strengthen muscle groups, but the glycemic control seems to be influenced primarily by the aerobic exercise. This underlines the importance of the aerobic exercise in the treatment and care of type 1 diabetes in childhood.

Further possibility is that early subclinical complications of diabetes or diabetic myopathy may contribute to reduced physical fitness achievements. Early complications can be present in children with diabetes, and in a previous trial, cardiovascular autonomic dysfunction interfered with exercise testing results [19]. Subtle microangiopathic vascular lesions and peripheral nerve dysfunction may lead to disturbed muscle innervations and some impairment in motor performance. However, in this study patients with early complications were not involved. Some evidences exist that diabetic myopathy may develop in type 1 diabetes [20]. To investigate whether very early microvascular, neuropathic, or muscle alterations may contribute to the impairment of motor or cardiorespiratory performances further studies are necessary.

In conclusion, both motor performance and cardiorespiratory fitness can be impaired in youths with type 1 diabetes. Independent relationship exists between metabolic control and cardiorespiratory fitness underlying the importance of life style interventions in the complex treatment and care of childhood diabetes. Regular and parallel assessments of motor and cardiorespiratory functions by the Eurofit battery tests may help to identify the individual needs of special exercise activities that contribute to better physical condition and metabolic control of children and adolescents with type 1 diabetes. However, further studies are necessary to explain the mechanisms by which diabetes leads to reduced fitness and to examine the effect of lifestyle intervention on the feasibility of improving cardiovascular fitness.

\section{Authors' contribution}

AL conceived the study; $\mathrm{AL}, \mathrm{KM}$ and $\mathrm{EJ}$ conducted the measurements, $\mathrm{AL}$ and $\mathrm{BV}$ conducted the statistical analysis; LB and FB contributed to the design of the study and 
revised the article for important intellectual content. All authors gave final approval of the version to be published.

\section{Funding}

This work was carried out as part of the TAMOP-4.2.1.B-10/2/KONV-2010-0001 project with support by the European Union, co-financed by the European Social Fund. Andrea Lukács was granted by the Hungarian Diabetes Association.

\section{Acknowledgements}

We are very grateful to all patients with type 1 diabetes and the control schoolboys and girls for taking part in this research study. We would like to thank to the physicians and assistants of the Pediatric Diabetes Centre for their interest and co-operation.

\section{Declaration of Competing Interests}

Nothing to declare

\section{REFERENCES}

1. American Diabetes Association. Physical activity/exercise and diabetes mellitus. Diabetes Care 2004; 27(Suppl. 1): S58-S62.

2. Robertson K, Adolfsson P, Riddell M, Scheiner G, Hanas R. Exercise in children and adolescents with diabetes. Pediatr Diabetes 2009; 10(Suppl. 12): 154-168.

3. Huttunen NP, Käär ML, Knip M, Mustonen A, Puukka R, Akerblom HK. Physical fitness of children and adolescents with insulin-dependent diabetes mellitus. Ann Clin Res 1984; 16: 1-5.

4. Maggio AB, Hofer MF, Martin XE, Marchand LM, Beghetti M, Farpour-Lambert NJ. Reduced physical activity level and cardiorespiratory fitness in children with chronic diseases. Eur J Pediatr 2010; 169: 1187-1193.

5. Wiśniewski A, Poliszczuk T, Pańkowska E. Assessment of physical fitness in children and teenagers with type 1 diabetes. Pediatr Endocrinol Diabetes Metab 2010; 16: 171175.

6. Williams BK, Guelfi KJ, Jones TW, Davis EA. Lower cardiorespiratory fitness in children with type 1 diabetes. Diab Med 2011; 28: 1005-1007.

7. Michaliszyn SF, Quinn L, Fritschi C, Faulkner MS. Physical fitness, dietary intake and metabolic control in adolescents with type 1 diabetes. Pediatr Diabetes 2009; 10: 389 394

8. Committee of Experts on Sports Research. Eurofit: Handbook for the Eurofit tests of physical fitness, $2^{\text {nd }}$ ed., 2003; Strasbourg: Council of Europe, Committee for the Development of sports

9. Hyde TE, Gengenbach MS. Conservative Management of Sports Injuries, $2^{\text {nd }}$ edn. 2007; Sudbury: Jones \& Bartlett, 845.

10. Léger LA, Lambert J. A maximal multistage 20-m shuttle run test to predict VO2 max. Eur J Appl Physiol Occup Physiol 1982; 49: 1-12.

11. Léger LA, Mercier D, Gadoury C, Lambert J. The multistage 20 metre shuttle run test for aerobic fitness. J Sports Sci 1988; 6: 93-101. 
12. Ramsbottom R, Brewer J, Williams C. A progressive shuttle run test to estimate maximal oxygen uptake. Br J Sports Med 1988; 22: 141-144

13. Liu NY, Plowman SA, Looney MA. The reliability and validity of the 20-meter shuttle test in American students 12 to 15 years old. Res Q Exerc Sport 1992; 63: 360-365.

14. Marfell-Jones M, Olds T, Stewart A, Carter L. International standards for anthropometric assessment. 2nd edn. 2006; Potchefstroom, South Africa, 57-66.

15. Kowalski K.C., Crocker P.R., Faulkner R.A. Validation of the physical activity questionnaire for older children. Pediatr Exerc Sci 1997; 9: 174-186.

16. Kowalski C.K., Crocker P.R., Kowalski N.P. Convergent validity of the physical activity questionnaire for adolescents. Pediatr Exerc Sci 1997; 9: 342-352.

17. Heyman E, Briard D, Gratas-Delamarche A, Delamarche P, De Kerdanet M. Normal physical working capacity in prepubertal children with type 1 diabetes compared with healthy controls. Acta Paediatr 2005; 94: 1389-1394.

18. Komatsu WR, Gabbay MA, Castro ML, Saraiva GL, Chacra AR, de Barros Neto, Dib SA et al. Aerobic exercise capacity in normal adolescents and those with type 1 diaebtes mellitus. Pediatr Diabetes 2005; 6: 145-149.

19. Barkai L, Peja M, Vámosi I. Physical work capacity in diabetic children and adolescents with and without cardiovascular autonomic dysfunction. Diabetic Med 1996; 13: 254-258.

20. Krause MP, Riddell MC, Hawke TJ. Effects of type 1diabetes mellitus on skeletal muscle: clinical observations and physiological mechanisms. Pediatr Diabetes 2011; 12: $345-364$. 
Table 1. Characteristics of the study participants (Diabetes $=106$, Control=130; mean $\pm S D$ )

\begin{tabular}{|c|c|c|c|c|}
\hline & $\begin{array}{l}\text { Girls with } \\
\text { diabetes }\end{array}$ & Control girls & $\begin{array}{l}\text { Girls with } \\
\text { diabetes }\end{array}$ & Control girls \\
\hline & $8-12 \mathrm{yr}$ & $8-12$ yr & $13-18 \mathrm{yr}$ & $13-18 \mathrm{yr}$ \\
\hline$n$ & 27 & 32 & 26 & 37 \\
\hline age (years) & $10.60 \pm 1.53$ & $10.80 \pm 1.15$ & $15.79 \pm 1.81$ & $16.01 \pm 1.84$ \\
\hline BMI $\left(\mathrm{kg} / \mathrm{m}^{2}\right)$ & $19.30 \pm 3.91$ & $17.17 \pm 3.78$ & $22.18 \pm 3.83$ & $21.37 \pm 4.25$ \\
\hline $\begin{array}{l}\text { sum of skinfolds } \\
(\mathrm{mm})\end{array}$ & $62.56 \pm 23.58$ & $56.44 \pm 27.45$ & $92.02 \pm 27.91$ & $83.48 \pm 27.10$ \\
\hline physical activity level & $2.37 \pm 1.28$ & $2.47 \pm 1.11$ & $2.04 \pm 1.37$ & $2.00 \pm 0.97$ \\
\hline $\begin{array}{l}\text { diabetes duration } \\
\text { (years) }\end{array}$ & $4.86 \pm 2.78$ & - & $5.73 \pm 2.80$ & - \\
\hline $\mathrm{HbA}_{1 \mathrm{c}}(\%)$ & $8.49 \pm 1.39$ & - & $8.96 \pm 1.20$ & - \\
\hline \multirow[t]{3}{*}{$\mathrm{HbA}_{1 \mathrm{c}}(\mathrm{mmol} / \mathrm{mol})$} & $69 \pm 11.30$ & & $74 \pm 9.91$ & \\
\hline & $\begin{array}{l}\text { Boys with } \\
\text { diabetes }\end{array}$ & Control boys & $\begin{array}{l}\text { Boys with } \\
\text { diabetes }\end{array}$ & Control boys \\
\hline & $8-12 \mathrm{yr}$ & $8-12 \mathrm{yr}$ & $13-18 \mathrm{yr}$ & $13-18 \mathrm{yr}$ \\
\hline$n$ & 25 & 28 & 28 & 33 \\
\hline age (years) & $10.53 \pm 1.50$ & $11.02 \pm 1.13$ & $15.76 \pm 1.75$ & $15.41 \pm 1.71$ \\
\hline $\mathrm{BMI}\left(\mathrm{kg} / \mathrm{m}^{2}\right)$ & $18.56 \pm 3.12$ & $19.21 \pm 3.74$ & $21.81 \pm 2.97$ & $21.15 \pm 3.29$ \\
\hline $\begin{array}{l}\text { sum of skinfolds } \\
(\mathrm{mm})\end{array}$ & $57.62 \pm 24.93$ & $63.44 \pm 31.47$ & $56.97 \pm 26.58$ & $52.49 \pm 22.41$ \\
\hline physical activity level & $3.00 \pm 1.68$ & $2.79 \pm 1.37$ & $2.82 \pm 1.49$ & $3.24 \pm 1.41$ \\
\hline $\begin{array}{l}\text { diabetes duration } \\
\text { (years) }\end{array}$ & $3.76 \pm 2.74$ & - & $6.14 \pm 4.02$ & - \\
\hline $\mathrm{HbA}_{1 \mathrm{c}}(\%)$ & $8.22 \pm 1.61$ & - & $8.52 \pm 1.53$ & - \\
\hline $\mathrm{HbA}_{1 \mathrm{c}}(\mathrm{mmol} / \mathrm{mol})$ & $66 \pm 12.92$ & & $70 \pm 12.57$ & \\
\hline
\end{tabular}

BMI, body mass index; $\mathrm{HbA}_{1 \mathrm{c}}$, haemoglobin $\mathrm{A}_{1 \mathrm{c}}$ 
Table 2. Eurofit test results of girls with type 1 diabetes compared to healthy control groups (mean $\pm \mathrm{SD}$ )

\begin{tabular}{|l|c|c|c|c|c|c|}
\hline & \multicolumn{2}{|c|}{ child girls $(8-12 \mathrm{yr})$} & & \multicolumn{2}{c|}{ adolescent girls 13-18 yr) } & \\
\hline Tests & Diabetes & Control & $\begin{array}{c}\mathrm{p} \\
\text { value }\end{array}$ & Diabetes & Control & $\begin{array}{c}\mathrm{p} \\
\text { value }\end{array}$ \\
\hline $\begin{array}{l}\text { FLB* (No of } \\
\text { error) }\end{array}$ & $8.33 \pm 4.35$ & $6.63 \pm 6.01$ & 0.095 & $9.65 \pm 6.52$ & $9.03 \pm 6.28$ & 0.716 \\
\hline PLT $\dagger(\mathrm{sec})$ & $16.60 \pm 3.23$ & $14.89 \pm 3.48$ & 0.022 & $14.32 \pm 1.80$ & $13.13 \pm 1.82$ & 0.013 \\
\hline SAR $(\mathrm{cm})$ & $19.17 \pm 5.48$ & $19.66 \pm 4.42$ & 0.951 & $22.52 \pm 6.40$ & $20.65 \pm 6.21$ & 0.250 \\
\hline SBJ $(\mathrm{cm})$ & 133.41 & 137.56 & 0.419 & 150.31 & 143.22 & 0.259 \\
& \pm 21.02 & \pm 18.17 & & \pm 24.86 & \pm 23.90 & \\
\hline HGR $(\mathrm{kg})$ & $19.44 \pm 4.73$ & $19.72 \pm 4.80$ & 0.826 & $30.31 \pm 4.73$ & $29.57 \pm 4.17$ & 0.514 \\
\hline SUP $(\mathrm{attempt})$ & $16.11 \pm 5.78$ & $20.63 \pm 5.43$ & 0.001 & $16.77 \pm 5.57$ & $19.41 \pm 4.19$ & 0.036 \\
\hline BAH $(\mathrm{sec})$ & $2.61 \pm 2.83$ & $5.98 \pm 7.39$ & 0.025 & $1.77 \pm 2.55$ & $4.58 \pm 5.41$ & 0.008 \\
\hline SHR $(\mathrm{sec})$ & $24.30 \pm 2.06$ & $23.16 \pm 2.09$ & 0.040 & $23.42 \pm 2.13$ & $23.28 \pm 2.25$ & 0.806 \\
\hline VO ${ }_{2 \mathrm{max}}$ & $43.14 \pm 4.33$ & $46.42 \pm 4.17$ & 0.006 & $33.27 \pm 4.80$ & $36.48 \pm 5.96$ & 0.015 \\
$(\mathrm{ml} / \mathrm{min} / \mathrm{kg})$ & & & & & & \\
\hline
\end{tabular}

BAH, bent arm hang; FLB, Flamingo balance; HGR, hand grip; PLT, plate tapping; SAR, sit and reach; SBJ, standing broad jump; SHR, $10 \times 5 \mathrm{~m}$ shuttle run; SUP, sit-ups.

*-numbers of steps down from the beam losing the balance

t-time for touching two discs 25 times back and forth

Table 3. Eurofit test results of boys with type 1 diabetes compared to healthy control groups (mean \pm SD)

\begin{tabular}{|c|c|c|c|c|c|c|}
\hline & \multicolumn{2}{|c|}{ child boys ( $8-12$ yr) } & & \multicolumn{2}{|c|}{ adolescent boys (13-18 yr) } & \\
\hline Tests & Diabetes & Control & $\begin{array}{c}\mathrm{p} \\
\text { value }\end{array}$ & Diabetes & Control & $\begin{array}{c}\mathrm{p} \\
\text { value }\end{array}$ \\
\hline $\begin{array}{l}\text { FLB* (No of } \\
\text { error) }\end{array}$ & $9.68 \pm 5.23$ & $7.18 \pm 6.01$ & 0.054 & $9.39 \pm 6.57$ & $6.58 \pm 5.75$ & 0.066 \\
\hline $\operatorname{PLT} \uparrow(\sec )$ & $17.39 \pm 3.40$ & $15.54 \pm 3.00$ & 0.025 & $13.16 \pm 1.47$ & $11.87 \pm 1.97$ & 0.006 \\
\hline SAR (cm) & $14.58 \pm 5.44$ & $18.23 \pm 4.41$ & 0.009 & $16.50 \pm 7.77$ & $20.63 \pm 7.46$ & 0.038 \\
\hline $\mathrm{SBJ}(\mathrm{cm})$ & $\begin{array}{l}146.64 \\
\pm 24.57\end{array}$ & $\begin{array}{l}151.25 \\
\pm 28.65\end{array}$ & 0.535 & $\begin{array}{l}195.50 \\
\pm 24.46\end{array}$ & $\begin{array}{l}201.15 \\
\pm 31.15\end{array}$ & 0.440 \\
\hline HGR (kg) & $21.04 \pm 6.06$ & $23.79 \pm 5.91$ & 0.050 & $39.64 \pm 8.52$ & $42.24 \pm 8.80$ & 0.248 \\
\hline SUP (attempt) & $19.80 \pm 4.97$ & $22.89 \pm 5.45$ & 0.036 & $23.39 \pm 4.18$ & $26.12 \pm 4.13$ & 0.013 \\
\hline $\mathrm{BAH}(\mathrm{sec})$ & $6.01 \pm 5.61$ & $6.00 \pm 5.96$ & 0.979 & $13.36 \pm 11.56$ & $\begin{array}{c}19.60 \\
\pm 12.92\end{array}$ & 0.030 \\
\hline SHR (sec) & $22.39 \pm 2.48$ & $21.80 \pm 3.32$ & 0.103 & $20.45 \pm 1.70$ & $19.96 \pm 2.51$ & 0.386 \\
\hline $\begin{array}{l}\mathrm{VO}_{2 \max } \\
(\mathrm{ml} / \mathrm{min} / \mathrm{kg})\end{array}$ & $45.58 \pm 3.30$ & $46.89 \pm 5.60$ & 0.298 & $38.72 \pm 5.20$ & $44.80 \pm 7.29$ & 0.000 \\
\hline
\end{tabular}

BAH, bent arm hang; FLB, Flamingo balance; HGR, hand grip; PLT, plate tapping; SAR, sit and reach; SBJ, standing broad jump; SHR, $10 \times 5$ m shuttle run; SUP, sit-ups.

*-numbers of steps down from the beam losing the balance

†-time for touching two discs 25 times back and forth 
Table 4. Summary of multiple regression analysis for $\mathrm{VO}_{2 \max }(\mathrm{N}=106)$

\begin{tabular}{lccccc}
\hline Variables & $\mathrm{B}$ & $\mathrm{SE}(\mathrm{B})$ & $\beta$ & $\mathrm{t}$ & $\mathrm{p}$ \\
\hline skinfold & -0.037 & 0.015 & -0.168 & -2.543 & 0.013 \\
thickness & & & & & \\
age & -1.261 & 0.126 & -0.606 & -10.001 & 0.000 \\
$\mathrm{HbA}_{1 \mathrm{c}}$ & -1.037 & 0.272 & -0.233 & -3.811 & 0.000 \\
gender & 2.248 & 0.820 & 0.176 & 2.740 & 0.007 \\
physical & 0.737 & 0.269 & 0.171 & 2.742 & 0.007 \\
activity & & & & & \\
\hline
\end{tabular}

$\mathrm{HbA}_{1 \mathrm{c}}$, haemoglobin $\mathrm{A}_{1 \mathrm{c}}$

$\mathrm{R}=0.807, \mathrm{R}^{2}=0.651, \mathrm{R}^{2}$ change $=-0.003$ (Sig. $\mathrm{F}$ Change=0.331) 